\title{
IMPACT OF EDUCATIONAL INTERVENTION ON THE PREVALENCE OF ANAEMIA AMONG GIRLS AND WOMEN OF REPRODUCTIVE AGE GROUP IN AN URBAN SLUM OF BHOPAL
}

\author{
Mahesh Gupta ${ }^{1}$, Daneshwar Singh ${ }^{2}$, Sharad Tiwari ${ }^{3}$, Seema Patel ${ }^{4}$, Angelina Priya ${ }^{5}$, Soumitra Sethia ${ }^{6}$, Abhisek Sahai $^{7}$
}

${ }_{1}^{1}$ Postgraduate Student, Department of Community Medicine, Gandhi Medical College (GMC), Bhopal. ${ }_{2}^{2}$ Postgraduate Student, Department of Community Medicine, Gandhi Medical College (GMC), Bhopal.

3 Postgraduate Student, Department of Community Medicine, Gandhi Medical College (GMC), Bhopal. 4 Postgraduate Student, Department of Community Medicine, Gandhi Medical College (GMC), Bhopal. 5 Postgraduate Student, Department of Community Medicine, Gandhi Medical College (GMC), Bhopal. ${ }^{6}$ Postgraduate Student, Department of Community Medicine, Gandhi Medical College (GMC), Bhopal. 7 Program Coordinator, Department of Community Medicine, Gandhi Medical College (GMC), Bhopal.

\section{ABSTRACT}

\section{BACKGROUND}

Anaemia is one of the most important health problems throughout the world. It is a global public health problem affecting both the developing and developed countries. Anaemia affects mainly the women of child bearing age group, young children and adolescent girls. In India, Nutritional anaemia is a major public health problem and is primarily due to iron deficiency, which is because of low intake of dietary iron. Considering the gravity of situation in India, the present study was planned. This is a small step to implicate the concept of preventive and social medicine through educational intervention to help the women combat anaemia. Intellectual investment in females will ultimately lead to intergenerational impact. This study aimed to examine the effect of educational intervention at door step.

Aim of the study is to study the prevalence of anaemia in the study population and to assess the effectiveness of educational intervention on Anaemia.

\section{MATERIALS AND METHODS}

The present interventional study included 336 girls/women of 15-45 years of age, non-probability purposive sampling technique was adopted for study.

Duration of the study period was December 2014 to March 2015. Study tool of semi-structured questionnaire with open ended questions was used to obtain the data regarding age, anthropometric measurements, socioeconomic status, their dietary habits and knowledge regarding awareness.

Statistical analysis - data obtained were collated and analysed statistically by mean \pm standard deviation (S.D.), percentages and simple proportions and were reported in the form of descriptive statistics. The Chi-square test was used for statistical analysis of qualitative data. The significance of the results was computed at the level of $p<0.05$.

\section{RESULTS}

Overall, before intervention $43.15 \%$ participants were having normal haemoglobin status and after intervention it significantly increased to $77.40 \%$. The mean haemoglobin before intervention was found to be $10.20 \mathrm{gm} \%( \pm 0.089)$ and after intervention mean haemoglobin was significantly increased to $11.69 \%( \pm 1.206)$ and $\mathrm{P}$ value $<0.05$.

\section{CONCLUSION}

The overall improvement in anaemia status among the study subjects is $22.6 \%$ from $56.84 \%$. The results of this study revealed that educational intervention approaches increase knowledge, health beliefs and behaviour.

\section{KEYWORDS}

Anaemia, Iron Folic Acid, Education, Community, Nutrition Problem.

HOW TO CITE THIS ARTICLE: Gupta M, Singh D, Tiwari S, et al. Impact of educational intervention on the prevalence of anaemia among girls and women of reproductive age group in an urban slum of Bhopal. J. Evolution Med. Dent. Sci. 2016;5(91):6790-6794, DOI: $10.14260 /$ jemds/2016/1534

\section{INTRODUCTION}

Anaemia is one of the most important health problems throughout the world.[1] It is a global public health problem affecting both the developing and developed countries.

Financial or Other, Competing Interest: None.

Submission 16-08-2016, Peer Review 30-08-2016,

Acceptance 15-09-2016, Published 14-11-2016.

Corresponding Author:

Dr. Mahesh Gupta,

Department of Community Medicine,

Gandhi Medical College, Bhopal.

E-mail:drmguptagmc@gmail.com

DOI: $10.14260 /$ jemds $/ 2016 / 1534$

\section{(c) (i) $\$$}

Anaemia affects mainly the women of childbearing age group, young children and adolescent girls.[2,3,4,5] Women of reproductive age are most at risk with global anaemia prevalence estimates of 42 percent in pregnant women and 30 percent in non-pregnant women aged 15-49 years.[6] Anaemia has major consequences on human health as well as social and economic development.

It is the world's second leading cause of disability and is responsible for about more than 115,000 maternal deaths and 591,000 perinatal deaths globally per year, of which three-quarters occur in Africa and South-East Asia.[4]

The very high prevalence of anaemia in South Asia to a large extent is due to predominantly vegetarian population. The causes of anaemia are diverse and multifactorial, but 
among the developing countries the leading aetiologies are mainly nutritional deficiencies (Especially of iron, folate and vitamin B12).[7] In India nutritional anaemia is a major public health problem and is primarily due to iron deficiency, which is because of low intake of dietary iron. The National Family Health Survey-4 (NFHS-4) data suggests that anaemia is widely prevalent among all age groups and is particularly high nearly $52.4 \%$, amongst them the most vulnerable are the women of Reproductive age group (15-49 years).[8] Considering the gravity of situation in India, the present study was planned. This is a small step towards the concept of preventive and social medicine through educational intervention to help the women combat anaemia. Intellectual investment in women will ultimately lead to intergenerational impact. This study aimed to examine the effect of educational intervention at doorstep.

\section{OBJECTIVE}

To study the prevalence of anaemia in the study population and to assess the effectiveness of educational intervention on Anaemia.
The present study is a community based educational intervention, this quasi-experimental study conducted door to door in girls/women of 15-45 years of age selected from Idgah Slum area (which was selected from total slums of Bhopal by random sampling) and the participants included all girls/women that were present during the visits. Those having severe anaemia were excluded, because they require supervised parenteral therapy and were advised to visit nearby hospital for appropriate treatment. The present interventional study included 336 girls/women of 15-45 years of age, non-probability purposive sampling technique was adopted for study. Participants were explained the purpose of the study and rapport was built up among community members and verbal consent was obtained from them. This study was carried out in phases, the first of which was questionnaire-based assessment, the second institution of audio-visual modules and the third was again a questionnaire-based assessment. An educational intervention was given in the form of audio-visual aid imparted with images, cartoons, videos using you tube and Microsoft Picture Manager were liberally used in order to convey the intended messages.

\section{MATERIALS AND METHODS}
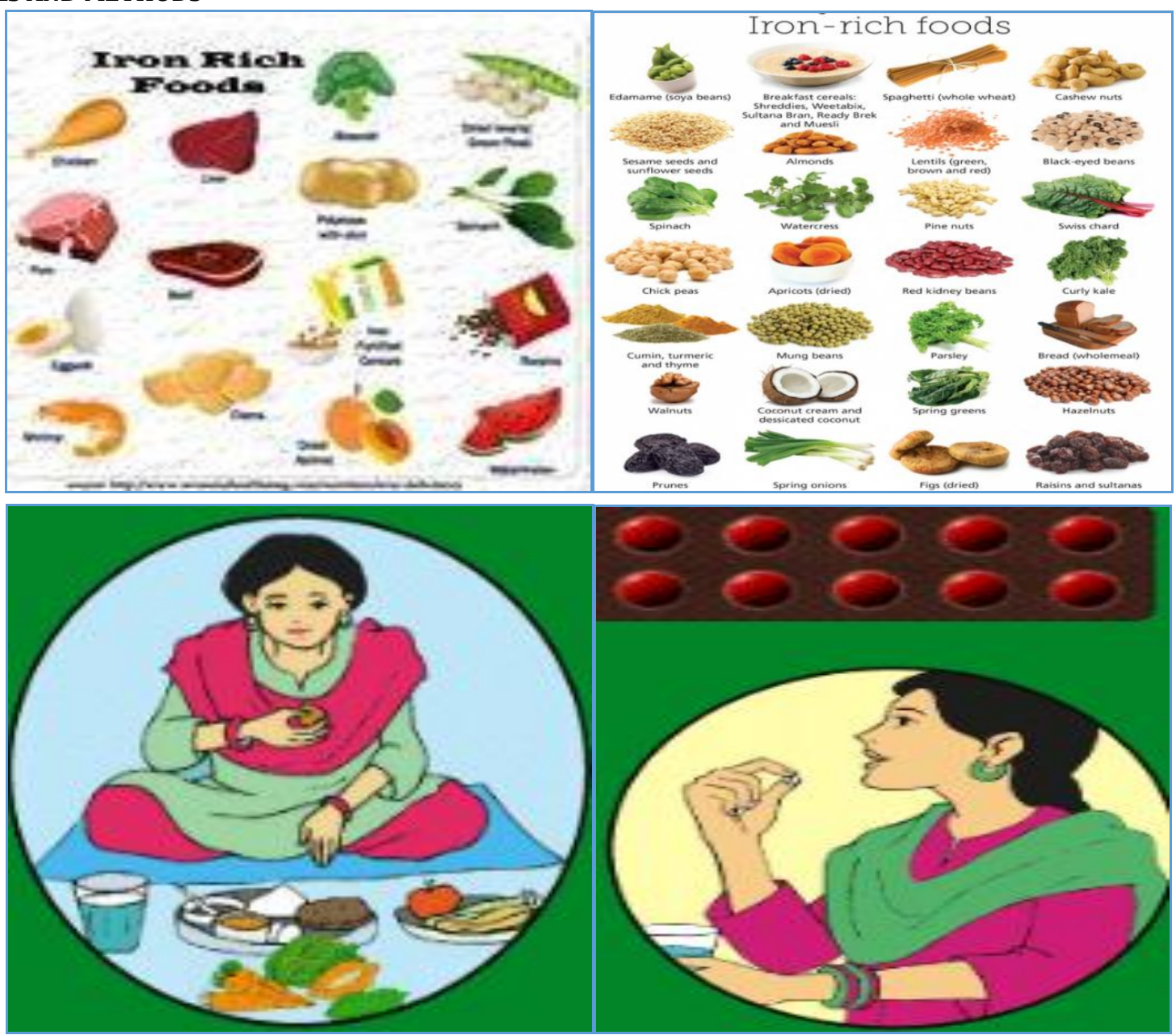

Fig. 1: Quick Look of the Visual Module. All the Images Used in this Module were in the Open Domains

\section{Duration of Study}

The study period was December 2014 to March 2015.

\section{Study Tool}

A semi-structured questionnaire with open ended questions was used to obtain the data regarding age, anthropometric measurements, socioeconomic status, their dietary habits and knowledge regarding awareness. Validity of the 
questionnaire can be judged by the impact of research design and the consistency of findings, analysis has been undertaken by a team of researchers rather than single researchers (inter-rater reliability). The developed questionnaire is revised by researchers and public health experts and then has been translated into both languages (Hindi and English).

\section{Data Collection and Procedure}

The anthropometric measurements such as height and weight were recorded using measuring tape and weighing machine with maximum accuracy. The Body Mass Index (BMI) was classified according to CDC guidelines.[9] The percentile BMI of participants was calculated at 5th, 85th and 95th percentile and the values of BMI for these percentiles were 13.2, 19.9 and 23, respectively. The socioeconomic status classification suggested by B. G. Prasad was adopted.[10] Haemoglobin estimation by using digital haemoglobin meter (portable, fully automated, measuring range: $5-25 \mathrm{gm} / \mathrm{dL}$ ) and the diagnosis is established as anaemia according to WHO guidelines.[11] All the girls/women were given a supervised single dose antihelminthic drug (Tab Albendazole $400 \mathrm{mg}$ ) and advice on healthy dietary practices with available resources such as use of jaggery, green-leafy vegetables, meat. The girls/women who were anaemic were given iron and folic acid tablets (ferrous sulphate $335 \mathrm{mg} \approx 100 \mathrm{mg}$ elemental iron and folic acid $500 \mu \mathrm{g}$ ) for daily consumption at home after meals and also were advised to take citrus fruits (lemon, amla, imli). The regular consumption of iron, folic acid tablets was assessed by periodic visits to their household and correcting faulty dietary practices. Counselling of each and every anaemic individual was done through interviews assisted with audiovisual aid. The consumption of iron tablets was ensured by collecting empty blister packs and then giving new tablets every 15 days. After 4 months of completion of treatment, haemoglobin $(\mathrm{Hb})$ was estimated by the same method for all anaemic girls/women.

\section{Statistical Analysis}

Due clearance was obtained and after taking departmental permission the community members were explained the purpose of the study and written informed consent was obtained from participants. Rapport was built up among them during initial visits. Data obtained were collated and entered in Microsoft Excel 2007 and analysed statistically using Epi Info $^{7}$ by mean \pm standard deviation (S.D.), percentages and simple proportions and were reported in the form of descriptive statistics. The Chi-square test was used for statistical analysis of qualitative data. The significance of the results was computed at the level of $p<0.05$.

\section{RESULTS}

In our study, prevalence of anaemia was $56.84 \%$ as shown in Figure 2 and was significantly higher in participants of low socioeconomic (III, IV, V) class $88(69.29 \%)$ as compared to anaemic participants belonging to upper socioeconomic (I, II) class (49.28\%) (Table 1). Anaemia was found to be significantly [P value $=0.0055]$, higher in illiterate $(65.71 \%$ ) as compared to literate $(50.51 \%)$ participants. Prevalence of anaemia on the basis of the weight and height were found to be insignificant. Prevalence of anaemia were found to be significantly $[\mathrm{P}$ value $=0.0425]$ higher among vegetarian $(62.42 \%)$ as compared to the non-vegetarian. Prevalence of anaemia was found to be significantly $[\mathrm{P}$ value < $\left.0.05^{*}(0.345)\right]$ higher among the participants of nuclear family as compared to the joint family. Out of total 191 girls/women who received intervention, $76 \%$ consumed it regularly and $24 \%$ consumed it irregularly due to the side effects of iron folic acid tablets such as metallic taste, nausea, fullness of abdomen and abdominal pain after its consumption. At the end of 3 months of intervention, four girls were lost for followup, thus it was possible to estimate haemoglobin level of 187 girls/women only. These four girls/women were absent even after repeated visit. [Figure 3] There was a significant post-intervention improvement in anaemia status among all the study subjects who were moderately anaemic and prevalence of moderate anaemia was reduced from $15.48 \%$ to $1.81 \%$ (i.e. the reduction of $13.67 \%$ ) and those study subjects who were mildly anaemic also significantly improved and prevalence of mild anaemia was reduced from $41.36 \%$ to $20.79 \%$ (i.e. the reduction of $20.57 \%$ ). Overall, before intervention $43.15 \%$ participants were having normal haemoglobin status and after intervention it significantly increased to $77.40 \%$.

\begin{tabular}{|c|c|c|c|c|}
\hline Sl. No. & Socio-Economic Status & Anaemia & Normal & P - value \\
\hline 1 & I,II & $103(49.28 \%)$ & $106(50.72 \%)$ & \multirow{2}{*}{$0.00033^{*}$} \\
\hline 2 & III, IV, V & $88(69.29 \%)$ & $39(30.71 \%)$ & \\
\hline \multicolumn{5}{|c|}{ Education } \\
\hline 1 & Illiterate & $92(65.71 \%)$ & $48(34.29 \%)$ & \multirow{2}{*}{$0.0055^{*}$} \\
\hline & Literate & $99(50.51 \%)$ & $97(49.49 \%)$ & \\
\hline \multicolumn{5}{|c|}{ BMI } \\
\hline 1 & Underweight & $16(64 \%)$ & $9(36 \%)$ & \multirow{4}{*}{0.863} \\
\hline 2 & Normal & $149(55.80 \%)$ & $118(44.20 \%)$ & \\
\hline 3 & Overweight & $14(58.33 \%)$ & $10(41.67 \%)$ & \\
\hline 4 & Obese & $12(60 \%)$ & $8(40 \%)$ & \\
\hline \multicolumn{5}{|c|}{ Diet } \\
\hline 1 & Vegetarians & $103(62.42 \%)$ & $62(37.58 \%)$ & \multirow{2}{*}{$0.0425^{*}$} \\
\hline 2 & Non-Vegetarians & $88(51.46 \%)$ & $83(48.54 \%)$ & \\
\hline \multicolumn{5}{|c|}{ Type of Family } \\
\hline 1 & Nuclear Family & 127 (61.35\%) & $80(38.65 \%)$ & \multirow{2}{*}{$0.0345^{*}$} \\
\hline 2 & Joint Family & $64(49.61 \%)$ & $65(50.39 \%)$ & \\
\hline Total & & $191(56.84 \%)$ & $145(43.15 \%)$ & \\
\hline
\end{tabular}




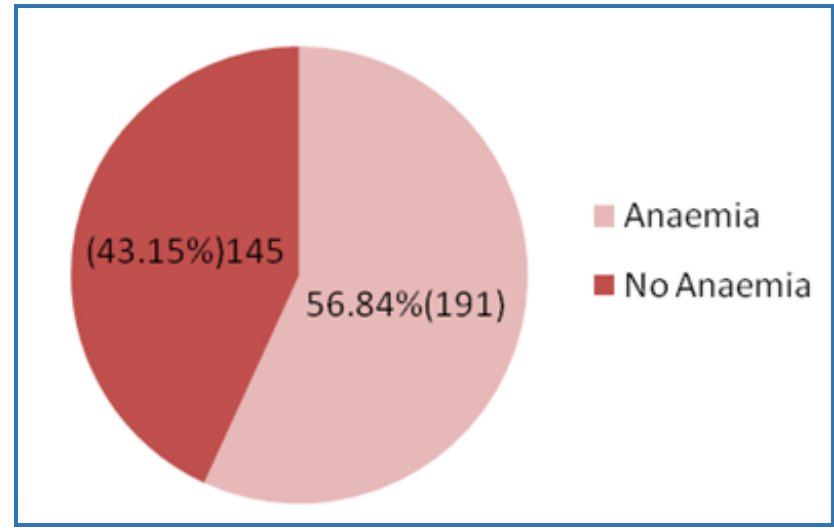

Fig. 2: Prevalence of Anaemia

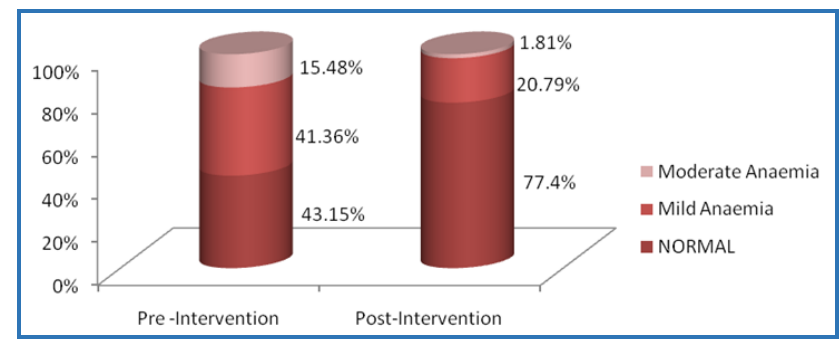

Fig. 3: Status of Anaemia of Study Group Before and After Intervention

\section{DISCUSSION}

In our study out of 336 girls/women 191 (56.84\%) girls/women were anaemic, 139 (41.15\%) participants were having mild anaemia and $52(15.48 \%)$ with moderate anaemia. These results were comparable with NFHS3, NFHS4 and similar results were reported by Singh et al[12] $50 \%$, Jawarkar AK et al[13] 54.8\%, Kaur S et al[14] 59.8\% and Rana et al[15] $60 \%$. Whereas higher prevalence has been reported in various study namely Devi S et al[16] 73\%, Chaturvedi et al[17] $(73.7 \%)$ and Toteja GS et al[18] found $90.1 \%$ may be due to the difference in the study area. Out of 336 participants, 103 (49.28\%) anaemic participants belonged to upper socioeconomic (I, II) class and 88 (69.29\%) anaemic participants to lower socio-economic (III, IV, V) class [P-value $=0.00033]$. Though anaemia is widely prevalent among females belonging to lower socio-economic strata of the society, it is not rare among the well-to-do classes of the society. Similar results were reported by Jawarkar et al[13] and Chaturvedi et al.[15] Anaemia were found to be significantly $[\mathrm{P}$ value $=0.0055)]$ associated with illiteracy $(65.71 \%)$ as compared to literate $(50.51 \%)$ participants. Similar results were reported by Jawarkar et al[13] and Chaturvedi et al.[15] Prevalence of anaemia on the basis of the weight and height were found to be insignificant. Similar results were reported by Jawarkar et al.[13] Prevalence of anaemia in the participants was unaffected, either they were underweight, normal or obese. Prevalence of anaemia were found to be significantly $[\mathrm{P}$ value $=0.0425]$ higher among vegetarian $(62.42 \%)$ as compared to the non-vegetarian. Similar findings were reported by Jawarkar et al[13] and Kaur et al.[16] The main cause of the dietary anaemia is inadequate food intake as well as poor availability of dietary iron in the habitual cereal based diets. Prevalence of anaemia found to be significantly $[\mathrm{P}$ value $=0.0345]$ higher among the participants of nuclear family as compared to the joint family. Similar results were also reported by Jawarkar et al.[13]
The results of the present study also indicate that there is remarkable improvement. The mean haemoglobin before intervention were found to be $10.20 \mathrm{gm} \%( \pm 0.089)$ and after intervention mean haemoglobin was significantly increased to $11.69 \%( \pm 1.206)$ and $P$ value $<0.05$.

\section{CONCLUSION}

The overall improvement in anaemia status among the study subjects is $22.6 \%$ from $56.84 \%$. In our study participants were more prone to be anaemic since they belonged to low socioeconomic status, illiterate, small family size and had vegetarian habits. There was an overall decrease in number of cases of anaemia after educational intervention.

To put an end towards it, important steps should be taken at individual and community level like education of the girls/women as regards anaemia, its causes and health implication. Imparting nutritional education with special emphasis on strategies based on locally available food stuffs to improve the dietary intake iron. The results of this study revealed that educational intervention approaches increase knowledge, health beliefs and behaviour. The results indicate that nutrition counselling in community level or door step can improve dietary intake and the concerned authority should mould their strategy through education based rather like programmatic implementation.

\section{RECOMMENDATIONS}

1. Need of healthy nutrition, necessity of balanced diet should incorporate in the education system in the form of Health topic/subject, so that adolescent age groups get maximum benefit of our education system.

2. The motivational educational session should be conducted in community with involvement of both community persons and health workers to bring awareness regarding healthy diet and about cheap sources of iron to improve nutritional deficiency.

3. There should be need of food fortification with iron such as salt, flour or oil; this will help to increase the iron in the food for long term in a sustainable manner. National cost effective strategies should be developed for the fortification of common people food.

\section{Relevance of the Study}

The study gives the glimpse that the anaemia is still high and draws the attention of the policy makers to review the gaps in existing policies for correcting anaemia.

\section{LIMITATIONS}

1. The cross-sectional nature of the study does not extend to the information on complete iron intake.

2. The data did not provide any information on food intake of respondents and therefore haemoglobin level of the population could not be correlated directly with the dietary regime.

\section{REFERENCES}

1. World Health Organization. National strategies for overcoming micronutrient malnutrition. WHO, Geneva, 1991.

2. WHO groups of experts on nutritional anemia. Technical report series. WHO, Geneva, 1986. 
3. Indian Council of Medical Research (ICMR). Evaluation of the national nutritional anaemia prophylaxis programmean ICMR task force study. ICMR, New Delhi: 1989.

4. Dreyfuss ML, Stoltzfus RJ, Shrestha JB, et al. Hookworms, malaria and vitamin A deficiency contribute to anemia and iron deficiency among pregnant women in the plains of Nepal. Journal of Nutrition 2000;130(10):2527-36.

5. Atukorala TM, de Silva LD, Dechering $\mathrm{WH}$, et al. Dassenaeike TS. Evaluation of effectiveness of iron-folate supplementation and anthelmintic therapy against anemia in pregnancy-a study in the plantation sector of Sri Lanka. American Journal of Clinical Nutrition 1994;60(2):286-92.

6. McLean E, Cogswell M, Egli I, et al. Worldwide prevalence of anaemia, WHO vitamin and mineral nutrition information system, 1993-2005. Public Health Nutr 2009;12(4):444-54.

7. Agarwal KN, Agarwal DK, Anshu S. Anaemia in pregnancyinterstate differences. Scientific report 16 by nutrition foundation of India. 2005:1-3.

8. National nutrition monitoring bureau, diet and nutritional status of rural population and prevalence of hypertension among adults in rural areas, NNMB technical report No. 24, NNMB, NIN, Hyderabad 2006.

9. WHO Expert Consultation. Appropriate body mass index for Asian populations and its implications for policy and intervention strategies. Lancet 2004;363(9403):157-63.

10. Baride JP, Kulakrni AP. Text book of community medicine. $3^{\text {rd }}$ edn. Mumbai, India: Vora Medical 2006:1235.

11. Nutritional status of children and prevalence of anemia among children, adolescent girls and pregnant women. District level household survey on reproductive and child health. Ministry of health and family welfare, Deemed University, New Delhi 2006:61.
12. Singh J, Singh JV, Srivastava AK, et al. Health status of adolescent girls in slums of Lucknow. Indian J Community Med 2006;31(2):1023.

13. Jawarkar AK, Lokare PO, Kizhatil A, et al. Prevalence of anaemia and effectiveness of iron supplementation in anaemic adolescent school girls at Amravati City, Maharashtra. Journal of Health Research and Reviews 2015;2(1):7-10.

14. Kaur S, Deshmukh PR, Garg BS. Epidemiological correlates of nutritional anemia in adolescent girls of rural Wardha. Indian J Community Med 2006;31(4):2558.

15. Rana T. Age at menarche-nutritional status and other associated factors in urban Hyderabad girls. Ph D. Thesis. Submitted to National Institute of Nutrition, Hyderabad, 1983.

16. Devi S, Deswal V, Verma R. Determination of factors for anaemia among school going adolescent girls in Haryana. International Journal of Basic and Applied Medical Sciences 2015;5(1):99-102.

17. Chaturvedi S, Kapil U, Gnanasekaran N, et al. Nutrient intake amongst adolescent girls belonging to poor socioeconomic group of rural area of Rajasthan. Indian Pediatr 1996;33(3):197-201.

18. Toteja GS, Singh P, Dhillon BS, et al. Prevalence of anaemia among pregnant women and adolescent girls in 16 districts of India. Food Nutr Bull 2006;27(4):311-5. 